\title{
Pengaruh Jenis Pelarut dan Perbandingan Bahan dengan Pelarut terhadap Ekstrak Warna Kulit Pisang Kepok (Musa paradisiaca F.).
}

\author{
I Gede Esti Widiantara, Ni Made Wartini*, Lutfi Suhendra \\ PS Teknologi Industri Pertanian, Fakultas Teknologi Pertanian, Universitas Udayana, Kampus Bukit \\ Jimbaran, Badung, Kode pos : 80361; Telp/Fax : (0361) 701801.
}

Diterima 12 Agustus 2019 / Disetujui 09 September 2019

\begin{abstract}
The aims of this study were to determine the effect of solvent type and their ratio between material and solvent on the color of banana peel extract.The experiment in this study using factorial randomized block design with two factor. The first factor was the solvent type which consists of three levels: $n$ hexsane, acetone, and ethanol. The second factor was the ratio of the solvent that consists of four levels: 1:6, 1:8, 1:10, and 1:12. The experiment were grouped into 2 group and its implementation in order to obtain 24 experimental units. Variables observed are yield, total carotenoid, and the best color intensity. The results of this study indicate that the comparison of ingredients with solvents significantly affected the total carotenoids and the level of redness $(a *)$ while the yield, brightness $\left(L^{*}\right)$, and yellowish level $(b *)$ had no effect. The interaction of solvent types significantly affected the total carotenoids and the level of redness $\left(a^{*}\right)$ while the interaction of solvent types on yield, brightness $\left(L^{*}\right)$, and yellowish level $(b *)$ had no effect. The type of ethanol solvent with a ratio of material to of solvent (1: 6) is the best solvent that produces extracts of banana peels which produce dye extracts with a yield characteristic of $2,40 \pm 0,11 \%$, carotenoids $0,67 \pm 0,00 \%, L^{*} 2,40 \pm 0,11, a^{*} 56,58 \pm 6,92, b^{*} 1,66 \pm 0,17$.
\end{abstract}

Keywords: Kepok banana peel, solvent type, ratio between material and solvent, extraction, natural coloring

\footnotetext{
*Korespondensi Penulis:

Email :md_wartini@unud.ac.id
} 


\section{PENDAHULUAN}

Tanaman pisang (Musaceaea sp.) merupakan tanaman penghasil buah terbanyak di Indonesia. Tanaman pisang di Indonesia dapat tumbuh subur baik di dataran tinggi maupun di dataran rendah, dari yang beriklim basah maupun yang beriklim kering. Buahnya setiap saat dapat di jumpai karena tidak tergantung oleh musim. Data Statistik dan Direkorat Jendral Hortikultura (2015) menunjukkan luas panen pisang di Indonesia mencapai 88,728 $\mathrm{Ha}$ per tahun 2015, di daerah Bali sendiri luas panen mencapai 4,375 Ha kebun pisang per tahun 2015. Di provinsi Bali mampu menghasilkan 189,441 ton buah pisang per tahunnya (BPS 2015),

Menurut Husni (2009), Pemanfaatan kulit pisang di Indonesia, masih terbatas sebagai campuran pakan ternak (20-30\%), pisang kapok memiliki kulit yang lebih tebal dan memiliki kandungan karotenoid total sebesar 6,203 $\pm 0,004 \mu \mathrm{g} / \mathrm{g}$. Hasil identifikasi ekstrak kasar kulit pisang menunjukkan pigmen karotenoid pada kulit pisang terdiri dari golongan zeaxatin, xantofil dan $\beta$ karoten, (Suparmi dan Prasetya, 2011), Pada proses ekstraksi, kulit pisang yang digunakan telah berbentuk bubuk, untuk mendapatkan bubuk kulit pisang dengan karakteristik warna terbaik perlu dilakukan proses perebusan dengan asam sitrat dalam proses pembuatannya (Tritanti dan Pranita, 2015). Senyawa yang terkandung dalam asam sitrat dapat mencegah pertumbuhan mikroba dan sehingga menghambat proses browning.

Perbandingan bahan dengan pelarut dalam proses ekstraksi mempengaruhi hasil yang didapat, semakin banyak pelarut yang digunakan maka semakin banyak senyawa yang dapat di ekstrak (Vogel, 1978). Hasil penelitian Suparmi dan Prasetya (2012) menggunakan rasio perbandingan bahan dan pelarut 1:10 dengan pelarut aseton menunjukan hasil yang didapatkan kandungan karotenoid pada kulit pisang ambon kuning sebesar 6,203 $\pm 0,004 \mu \mathrm{g} / \mathrm{g}$. Penelitian yang dilakukan Ikawati (2005) rasio bahan terhadap pelarut yang menghasilkan ekstrak karotenoid terbaik adalah 1:8 menggunakan pelarut asetonmetanol. Peneitian yang dilakukan oleh Moulana et al.(2012) jenis pelarut berpengaruh sangat nyata terhadap intensitas warna yang dihasilkan.

Atas dasar hal-hal tersebut diastas dilakukan penelitian untuk mengetahui pengaruh jenis pelarut dan perbandingan bahan dengan pelarut terhadap warna ektrak kulit pisang kepok.

\section{Tempat dan Waktu Kegiatan}

Penelitian ini akan dilakukan di Laboratorium Pengolahan Pangan, Laboratorium Analisis Pangan dan Laboratorium Rekayasa Proses dan Pengendalian Mutu Fakultas Teknologi Pertanian Universitas Udayana Waktu pelaksanaan penelitian mulai Juni sampai Agustus 2018.

\section{Alat dan Bahan}

Peralatan yang akan digunakan dalam penelitian ini yaitu : rotary evaporator (Janke \& Kunkel RV 06 - ML), vortex (Thermoline), spekrofotometer uv-vis (Genesys 10s uv-vis), ayakan 40 mesh, aluminium foil, tisu, botol timbangan, botol sampel, pisau, blender (Philips), termometer, kertas saring kasar, kertas saring Whatman No.1, pipet volume, tabung reaksi, timbangan analitik (Shimadzu), pipet tetes, gelas beker (Pyrex), color reader (Accuprobe HH-06), labu Erlenmeyer (Pyrex), labu ukur (Iwaki), incubator dan kertas label, pipet mikro dan pinset.

Bahan utama pada penelitian ini adalah kulit buah pisang kepok yang diperoleh dari pedagang gorengan di Desa Kerobokan, Kecamatan Kuta Utara, Kabupaten Badung dengan kriteria warna 
kuning tua, sedangkan bahan kimia yang digunakan antara lain pelarut untuk ekstraksi n-heksana, etanol dan aseton yang semua mempunyai grade teknis yang didapat di Toko Bratachem, pelarut untuk analisis yaitu : kloroform, $\mathrm{NaSO}_{4}$, benzena, aseton dan akuades yang semua mempunyai grade pro analysis (pa).

\section{Rancangan Percobaan}

Penelitian ini merupakan penelitian Rancangan Acak Kelompok (RAK). Faktor I yaitu jenis pelarut $(\mathrm{P})$, terdiri atas tiga jenis pelarut yaitu n-heksana, Aseton, Etanol Faktor II yaitu perbandingan bahan dengan pelarut $(\mathrm{T})$, terdiri atas 4 taraf yaitu Perbandingan bahan dengan pelarut 1: $6,1: 8$, 1: 10 dan 1: 12. Dari 2 faktor di atas diperoleh 12 kombinasi perlakuan masingmasing dikelompokan dalam 2 kelompok sehingga diperoleh 24 unit percobaan. Data obyektif diperoleh dengan analisis ragam (Analysis of Variant atau ANOVA) dan dilanjutkan dengan uji Duncan apabila perlakuan berpengaruh terhadap variabel yang diamati. Perlakuan terbaik diperoleh dengan mempertimbangkan hasil rendemen, total karotenoid, dan intensitas warna ( $\mathrm{L}^{*}, \mathrm{a}^{*}$, $\left.\mathrm{b}^{*}\right)$ dengan menggunakan uji indeks efektivitas (De Garmo et al., 1984).

\section{HASIL DAN PEMBAHASAN}

\section{Rendemen}

Hasil analisis ragam menunjukkan bahwa jenis pelarut, perbandingan bahan dengan pelarut, dan interaksinya berpengaruh tidak nyata $(p>0,05)$ terhadap rendemen ekstrak kulit pisang (Lampiran 1). Nilai ratarata rendemen dapat dilihat pada Tabel 1.

Tabel 1. Nilai rata-rata rendemen ekstrak warna kulit pisang kepok (\%)

\begin{tabular}{ccccc}
\hline $\begin{array}{c}\text { Perbandingan Bahan } \\
\text { dengan Pelarut }\end{array}$ & \multicolumn{3}{c}{ Jenis Pelarut } & Rata- \\
\cline { 2 - 4 } Rata
\end{tabular}

Keterangan: Huruf berbeda di belakang nilai rata-rata menunjukkkan perbedaan yang sangat nyata $(p>0,05)$. Data merupakan rata-rata dari dua kelompok.

Tabel 1 menunjukkan bahwa nilai rata-rata rendemen ekstrak kulit pisang pada semua perlakuan perbandingan bahan dengan pelarut dan jenis pelarut menghasilkan nilai yang dihasilkan $(4,92 \%)$ dan tidak berpengaruh nyata.

Tabel 1 menunjukkan bahwa banyaknya senyawa yang larut dalam pelarut dalam n-heksan, aseton, etanol tidak berbeda dikarenakan senyawa tersebut mempunyai polaritas yang sama dengan n-heksan, aseton, etanol pada semua perbandingan.

Utami (2009) menyatakan bahwa waktu maserasi yang tepat akan menghasilkan rendemen ekstrak senyawa yang tinggi. Waktu maserasi yang terlalu singkat akan mengakibatkan tidak semua senyawa larut dalam pelarut yang digunakan, dan apabila waktu ekstraksi terlalu lama maka senyawa yang diekstrak akan rusak.

\section{Kadar Total Karotenoid}

Hasil analisis ragam menunjukkan bahwa perbandingan bahan dengan pelarut dan interaksi berpengaruh nyata dan perlakuan dengan bahan dengan pelarut berpengaruh sangat nyata $(p<0,01)$, jenis pelarut terhadap total karotenoid ekstrak warna kulit pisang (Lampiran 2). Nilai ratarata kadar total karotenoid dapat dilihat pada 
Tabel 2.

Tabel 2. Nilai rata-rata kadar total karotenoid ekstrak warna kulit pisang kepok (\%)

\begin{tabular}{cccc}
\hline \multirow{2}{*}{$\begin{array}{c}\text { Perbandingan Bahan } \\
\text { dengan Pelarut }\end{array}$} & n-heksan & Aseton & Etanol \\
\cline { 2 - 4 } $1: 6$ & $0,45 \pm 0,12^{\mathrm{b}}$ & $0,66 \pm 0,01^{\mathrm{a}}$ & $0,67 \pm 0,00^{\mathrm{a}}$ \\
$1: 8$ & $0,31 \pm 0,07^{\mathrm{c}}$ & $0,30 \pm 0,03^{\mathrm{c}}$ & $0,26 \pm 0,01^{\mathrm{c}}$ \\
$1: 10$ & $0,20 \pm 0,01^{\mathrm{d}}$ & $0,20 \pm 0,01^{\mathrm{d}}$ & $0,21 \pm 0,01^{\mathrm{d}}$ \\
$1: 12$ & $0,12 \pm 0,01^{\mathrm{e}}$ & $0,16 \pm 0,02^{\mathrm{d}}$ & $0,20 \pm 0,03^{\mathrm{d}}$
\end{tabular}

Keterangan: Huruf berbeda di belakang nilai rata-rata menunjukkkan perbedaan yang sangat nyata $(\mathrm{p}<0,01)$. Data merupakan rata-rata dari dua kelompok.

Tabel 2 menunjukkan bahwa nilai rata-rata kadar total karotenoid tertinggi dihasilkan pada perlakuan perbandingan bahan dengan pelarut $(1: 6)$ dengan jenis pelarut etanol (0,67\%). Gross (1991) bahwa kepolaran etanol mendekati kepolaran karotenoid. Semakin banyak perbandingan bahan dengan pelarut terjadi penurunan kadar total karotenoid kemungkinan terjadi karena kerusakan selama proses evaporasi, mengingat waktu yang diperlukan selama proses memiliki kadar karotenoid volume yang dievaporasi banyak.

\section{Intensitas Warna Tingkat kecerahan $\left(L^{*}\right)$}

Hasil analisis ragam menunjukkan bahwa jenis pelarut dan perbandingan bahan dengan pelarut dan interaksinya berpengaruh tidak nyata $(p>0,05)$ terhadap tingkat kecerahan ekstrak warna kulit pisang (Lampiran 3). Nilai tingkat kecerahan ( $\mathrm{L}^{*}$ ) menyatakan tingkat gelap sampai terang dengan kisaran 1 sampai +100 . Nilai rata-rata tingkat kecerahan kulit pisang dapat dilihat pada Tabel 3.

Tabel 3. Nilai rata-rata tingkat kecerahan (L*) ekstrak warna kulit pisang kepok (\%)

\begin{tabular}{ccccc}
\hline \multirow{2}{*}{$\begin{array}{c}\text { Perbandingan Bahan } \\
\text { dengan Pelarut }\end{array}$} & n-heksan & Aseton & etanol & $\begin{array}{c}\text { Rata- } \\
\text { Rata }\end{array}$ \\
\cline { 2 - 4 } & & & & \\
\hline $1: 6$ & $2,38 \pm 0,00$ & $2,32 \pm 0,01$ & $2,40 \pm 0,11$ & $2,36 \pm 0,04$ \\
$1: 8$ & $2,36 \pm 0,01$ & $2,37 \pm 0,06$ & $2,59 \pm 0,31$ & $2,43 \pm 0,12$ \\
$1: 10$ & $2,30 \pm 0,01$ & $4,92 \pm 3,54$ & $2,38 \pm 0,03$ & $3,2 \pm 1,19$ \\
$1: 12$ & $2,26 \pm 0,17$ & $2,51 \pm 0,13$ & $2,38 \pm 0,00$ & $2,38 \pm 0,10$ \\
Rata-rata & $2,32 \pm 0,04$ & $3,03 \pm 0,93$ & $2,43 \pm 0,11$ & \\
\hline
\end{tabular}

Keterangan: Huruf berbeda di belakang nilai rata-rata menunjukkkan perbedaan yang sangat nyata $(\mathrm{p}>0,05)$. Data merupakan rata-rata dari dua kelompok.

Tabel 3 menunjukkan bahwa tingkat kecerahan ekstrak tidak dipengaruhi jenis pelarut dan perbandingan bahan dengan pelarut. Semua perlakuan menghasilkan ekstrak warna kulit pisang tidak berbeda. Kemungkinan warna yang dihasilkan ekstrak warna kulit pisang tidak terlalu pekat.

\section{Tingkat kemerahan $\left(\mathrm{a}^{*}\right)$}

Hasil analisis ragam menunjukkan bahwa perlakuan perbandingan bahan dengan pelarut, jenis pelarut dan interaksinya berpengaruh nyata $(p>0,01)$ terhadap tingkat kemerahan ekstrak kulit pisang (Lampiran 4). Nilai tingkat kemerahan $\left(\mathrm{a}^{*}\right)$ menyatakan tingkat hijau sampai merah dengan kisaran 1 
sampai +100. Nilai rata-rata tingkat Tabel 4. kecerahan kulit pisang dapat dilihat pada

Tabel 4. Nilai rata-rata tingkat kemerahan (a*) ektrak warna kulit pisang kepok (\%)

\begin{tabular}{cccc}
\hline Perbandingan Bahan dengan & \multicolumn{3}{c}{ Jenis Pelarut } \\
\cline { 2 - 4 } Pelarut & n-heksan & Aseton & Etanol \\
\hline $1: 6$ & $64,23 \pm 0,68^{\mathrm{a}}$ & $58,31 \pm 4,94^{\mathrm{b}}$ & $56,58 \pm 6,92^{\mathrm{b}}$ \\
$1: 8$ & $60,36 \pm 1,41^{\mathrm{a}}$ & $47,36 \pm 0,74^{\mathrm{b}}$ & $55,65 \pm 0,71^{\mathrm{b}}$ \\
$1: 10$ & $58,09 \pm 5,26^{\mathrm{a}}$ & $40,93 \pm 2,26^{\mathrm{b}}$ & $54,09 \pm 0,85^{\mathrm{c}}$ \\
$1: 12$ & $55,16 \pm 6,36^{\mathrm{a}}$ & $55,42 \pm 0,01^{\mathrm{b}}$ & $56,37 \pm 0,28^{\mathrm{d}}$ \\
\hline
\end{tabular}

Keterangan: huruf berbeda di belakang nilai rata-rata menunjukkkan perbedaan yang sangat nyata ( $\mathrm{p}>0,01)$. Data merupakan rata-rata dari dua kelompok.

Tabel 4 menyatakan bahwa nilai ratarata tingkat kemerahan tertinggi diperoleh pada jenis pelarut $n$-heksan dengan perlakuan perbandingan bahan dengan pelarut (1:6) tingkat kemerahan yang dihasilkan $(64,23)$. Berbanding terbalik dengan nilai rata-rata tingkat kemerahan terendah diperoleh pada jenis pelarut aseton dengan perlakuan perbandingan bahan dengan pelarut (1:10) tingkat kemerahan yang dihasilkan $(40,93)$. Hasil penelitian Wahyuni dan Widjanarko (2015) tentang pengaruh jenis pelarut dan lama ekstraksi terhadap ekstrak karotenoid labu kuning dengan metode gelombang ultrasonik, menunjukkan tingkat kemerahan tertinggi diperoleh dari jenis pelarut $n$-heksan dibandingkan dengan jenis pelarut aseton dan etil asetat. Warna kemerahan tidak hanya dihasilkan oleh karoten saja, tetapi ada senyawa lain yang ada dalam kulit pisang yang mempengaruhi warna kemerahan tersebut, yaitu likopena, karotena, lutein, dan zeaxantin.

\section{Tingkat kekuningan (b*)}

Hasil analisis ragam menunjukkan bahwa jenis pelarut berpengaruh nyata $(\mathrm{P}<0.05)$ dan perbandingan bahan dengan pelarut dan interaksinya berpengaruh tidak nyata $(\mathrm{P}>0.05)$ terhadap tingkat kekuningan ekstrak warna kulit pisang (Lampiran 5). Nilai tingkat kekuningan menyatakan tingkat biru sampai kuning dengan kisaran 1 sampai +100 . Nilai rata-rata tingkat kekuningan kulit pisang dapat dilihat pada Tabel 5.

Tabel 5. Nilai rata-rata tingkat kekuningan $\left(\mathrm{b}^{*}\right)$ ekstrak warna kulit pisang kepok (\%)

\begin{tabular}{ccccc}
\hline \multirow{2}{*}{$\begin{array}{c}\text { Perbandingan Bahan } \\
\text { dengan Pelarut }\end{array}$} & n-heksan & Aseton & Etanol & Rata-Rata \\
\cline { 2 - 4 } & $3,96 \pm 0,56$ & $1,66 \pm 0.33$ & $1,66 \pm 0,17$ & $2,42 \pm 2,65^{\text {a }}$ \\
$1: 6$ & $2,30 \pm 0,66$ & $2,84 \pm 0,08$ & $1,72 \pm 0,69$ & $2,28 \pm 1,25^{\text {a }}$ \\
$1: 8$ & $2,40 \pm 1,14$ & $2,11 \pm 0,78$ & $1,74 \pm 0,41$ & $2,08 \pm 0,53^{\text {a }}$ \\
$1: 10$ & $3,41 \pm 0,72$ & $2,08 \pm 0,14$ & $2,90 \pm 0,78$ & $2,79 \pm 0,94^{\text {a }}$ \\
$1: 12$ & $3,03 \pm 1,93^{\text {a }}$ & $2,17 \pm 0,98^{\mathrm{b}}$ & $2,0 \pm 1,19^{\mathrm{b}}$ & \\
\hline Rata Rata & & &
\end{tabular}

Keterangan: huruf berbeda di belakang nilai rata-rata pada baris atau kolom yang sama menunjukkan perbedaan yang sangat nyata $(\mathrm{P}<0,05)$. Data merupakan rata-rata dari dua kelompok

Tabel 5 menyatakan bahwa nilai ratarata tingkat kekuningan $\left(b^{*}\right)$ pada semua perlakuan tidak berbeda. Nilai ( $\left.b^{*}\right)$ menunjukkan kecenderungan warna dari biru 
sampai kuning. Uji pelarut sangat nyata sedangkan interaksi dan perbandingan dengan pelarut tidak berpengaruh nyata, secara visual menunjukkan bahwa pelarut nheksan mendekati warna kekuningan. Pelarut dapat mengekstrak senyawa-senyawa yang memiliki kepolaran yang sama atau mirip dengan kepolaran pelarut yang digunakan. Menurut Shriner et al. (1980) pelarut polar akan melarutkan senyawa polar dan pelarut non polar akan melarutkan senyawa non polar.

\section{Uji Indeks Efektivitas}

Uji indeks efektivitas bertujuan untuk menetukan perlakuan terbaik dalam menghasilkan ektrak pewarna. Dalam uji ini digunakan nilai dari variabel yang diamati yaitu : rendemen, total karotenoid dan intensitas warna (tingkat kecerahan $\mathrm{L}^{*}$, tingkat kemerahan $a^{*}$, tingkat kekuningan $b^{*}$ ) (Lampiran 6). Uji indeks efektivitas dapat dilihat pada tabel 6 menunjukan bahwa perlakuan pelarut $n$-heksam mempunyai nilai tertinggi yaitu 39,16 sehingga perlakuan pelarut n-heksan merupakan perlakuan terbaik dibandingkan dengan perlakuan lain untuk menghasilkan efek pewarna.

\begin{tabular}{|c|c|c|c|c|c|c|c|}
\hline \multirow[b]{2}{*}{ Perlakuan } & \multicolumn{6}{|c|}{ Variabel } & \multirow[b]{2}{*}{ Jumlah } \\
\hline & & Rendemen & $\begin{array}{c}\text { Total } \\
\text { Karotenoid }\end{array}$ & $\mathrm{L}^{*}$ & $a^{*}$ & $b^{*}$ & \\
\hline & BV & 0,56 & 0,96 & 0,32 & 0,64 & 0,68 & 3,16 \\
\hline & $\mathrm{BN}$ & 0,18 & 0,3 & 0,1 & 0,2 & 0,22 & 1,00 \\
\hline \multirow{2}{*}{ n-heksan, 1:6 } & $\mathrm{Ne}$ & 0,05 & 0,60 & 0,95 & 1,00 & 0,16 & \\
\hline & $\mathrm{Nh}$ & 0,01 & 0,18 & 0,10 & 0,20 & 0,04 & 0,52 \\
\hline \multirow{2}{*}{ n-heksan, 1:8 } & $\mathrm{Ne}$ & 0,04 & 0,35 & 0,96 & 0,83 & 0,11 & \\
\hline & $\mathrm{Nh}$ & 0,01 & 0,11 & 0,10 & 0,17 & 0,02 & 0,40 \\
\hline \multirow{2}{*}{ n-heksan, 1:10 } & $\mathrm{Ne}$ & 0,01 & 0,16 & 0,99 & 0,76 & 0,04 & \\
\hline & $\mathrm{Nh}$ & 0,00 & 0,05 & 0,10 & 0,15 & 0,01 & 0,31 \\
\hline \multirow{2}{*}{ n-heksan, 1:12 } & $\mathrm{Ne}$ & 0,00 & 0,00 & 1,00 & 0,61 & 0,00 & \\
\hline & $\mathrm{Nh}$ & 0,00 & 0,00 & 0,10 & 0,12 & 0,00 & 0,22 \\
\hline \multirow{2}{*}{ Aseton, 1:6 } & $\mathrm{Ne}$ & 0,02 & 0,96 & 0,98 & 0,75 & 0,22 & \\
\hline & $\mathrm{Nh}$ & 0,00 & 0,29 & 0,10 & 0,15 & 0,05 & 0,59 \\
\hline \multirow{2}{*}{ Aseton, 1:8 } & $\mathrm{Ne}$ & 0,04 & 0,34 & 0,96 & 0,28 & 0,11 & \\
\hline & $\mathrm{Nh}$ & 0,01 & 0,10 & 0,10 & 0,06 & 0,02 & 0,29 \\
\hline \multirow{2}{*}{ Aseton, 1:10 } & $\mathrm{Ne}$ & 1,00 & 0,15 & 0,00 & 0,00 & 1,00 & \\
\hline & $\mathrm{Nh}$ & 0,18 & 0,04 & 0,00 & 0,00 & 0,21 & 0,44 \\
\hline \multirow{2}{*}{ Aseton, 1:12 } & $\mathrm{Ne}$ & 0,10 & 0,08 & 0,90 & 0,62 & 0,11 & \\
\hline & $\mathrm{Nh}$ & 0,02 & 0,03 & 0,09 & 0,13 & 0,02 & 0,28 \\
\hline \multirow{2}{*}{ Etanol, 1:6 } & $\mathrm{Ne}$ & 0,05 & 1,00 & 0,95 & 0,67 & 0,25 & \\
\hline & $\mathrm{Nh}$ & 0,01 & 0,30 & 0,10 & 0,14 & 0,05 & 0,60 \\
\hline \multirow{2}{*}{ Etanol, 1:8 } & $\mathrm{Ne}$ & 0,12 & 0,27 & 0,85 & 0,63 & 0,17 & \\
\hline & $\mathrm{Nh}$ & 0,02 & 0,08 & 0,16 & 0,13 & 0,04 & 0,43 \\
\hline \multirow{2}{*}{ Etanol, 1:10 } & $\mathrm{Ne}$ & 0,05 & 0,17 & 0,85 & 0,56 & 0,08 & \\
\hline & $\mathrm{Nh}$ & 0,01 & 0,05 & 0,16 & 0,11 & 0,02 & 0,35 \\
\hline \multirow{2}{*}{ Etanol, 1:12 } & $\mathrm{Ne}$ & 0,05 & 0,15 & 0,85 & 0,66 & 0,07 & \\
\hline & $\mathrm{Nh}$ & 0,01 & 0,05 & 0,09 & 0,13 & 0,02 & 0,29 \\
\hline
\end{tabular}

Keterangan :

$\mathrm{BV}=$ bobot variabel

$\mathrm{Ne}=$ nilai efektivitas
$\mathrm{BN}=$ bobot normal

$\mathrm{Nh}=$ nilai hasil $(\mathrm{Ne} \times \mathrm{BN})$ 


\section{KESIMPULAN DAN SARAN}

\section{Kesimpulan}

Berdasarkan penelitian yang telah dilakukan, dapat disimpulkan sebagai berikut:

1. Perbandingan bahan dengan pelarut berpengaruh nyata terhadap total karotenoid dan tingkat kemerahan $\left(a^{*}\right)$ sedangkan tidak berpengaruh terhadap rendemen, tingkat kecerahan $\left(\mathrm{L}^{*}\right)$, dan tingkat kekuningan $\left(b^{*}\right)$. Interaksi jenis pelarut berpengaruh nyata terhadap total karotenoid dan tingkat kemerahan $\left(\mathrm{a}^{*}\right)$ sedangkan interaksi jenis pelarut tidak berpengaruh terhadap rendemen, tingkat kecerahan $\left(\mathrm{L}^{*}\right)$, dan tingkat kekuningan (b*).

2. Jenis pelarut etanol dengan perbandingan bahan dengan jenis pelarut (1:6) merupakan pelarut terbaik yang menghasilkan ekstrak pewarna kulit pisang yang menghasilkan ekstrak pewarna dengan karakteristik rendemen $2,40 \% \pm 0,11$, karotenoid $0,67 \% \pm 0,00$, L* 2,40 $\pm 0,11, a^{*} 56,58 \pm 6,92, b^{*} 1,66 \pm$ 0,17

\section{Saran}

Untuk menghasilkan ekstrak warna kulit pisang kepok sebaiknya mengguanakan pelarut etanol (1:6) yang menghasilkan ekstrak pewarna dengan rendemen $2,40 \% \pm$ 0,11 , karotenoid $0,67 \% \pm 0,00, L^{*} 2,40 \pm$ $0,11, a^{*} 56,58 \pm 6,92, b^{*} 1,66 \pm 0,17$. Perlu dilakukan penelitian lebih lanjut mengenai stabilitas warna kulit pisang selama penyimpanan dan aplikasinya pada produk pangan.

\section{DAFTAR PUSTAKA}

\section{A.1.Vogel. 1978. Text Book Of Practical}

Organic Chemistry. The English language Book Society and Longmann p.1368

Badan Pusat Statistik. 2016. Tabel Produksi Tanaman Buah PisangTahun 2015. Diambil pada tanggal 1 Desember 2016,

Dari https://www.bps.go.id/site/chartResult $\underline{\mathrm{Tab}}$

Bernasconi, G., H. Gerster, H. Hauser, H. Stauble and E. Scheneifer. 1995. Teknologi Kimia. Bagian 2. Penerjemah: Handjojo L. dan Pradnya Paramita. Jakarta

Gross, J. 1991. Pigments in Vegetable (Chlorophylls and Carotenoid). Van Nostrand Reinhold. New York. 7. 75

Husni, I., 2009. Prespektif Industri Pisang Terpadu (Guna Peningkatan Nilai Tambah Komoditas), Direktorat budidaya Tanaman Buah Direktorat Jenderal Hortikultura Departemen Pertanian, http://ditbuah.hortikultura.deptan.go.id Diakses 2 Desember 2016

Ikawati ratna. 2005. Optimasi Kondisi Ekstraksi Karotenoid Wortel (daucus carota L). Menggunakan Response Surface Methodology (RSM). Jurnal teknologi pertanian. Vol. 1, No. 1, pp. 14-22. Samarinda.

Khuluq, A. D., S. B Widjanarko dan E. S. Murtini. 2007. Ekstraksi dan Stabilitas Betasianin Daun Darah (Alternantera dentata) (Kajian Perbandingan Pelarut Air, Etanol, dan Suhu Ekstraksi). Jurnal Teknologi Pertanian. Volume 8 Nomor 3 Desember 2007

Moulana Ryan, Juanda, Rohaya Syarifah, Rosika Ria. 2012. Efwktivitas Penggunaan Jenis Pelarut dan Asam Dalam Proses Ektraksi Pigmen Antosiannin Kelopak Bunga Rosella 
(Hibiscus Sabdariffa L), Jurnal Teknologi dan Industri Pertanian Indonesia 3 (3); Universitas Syah Kuala.

Shriner, R. L., R. C. Fuson., D. Y. Curtin., C. K. F. Herman and T. C. Moroli. 1980. The Systematic Identification of Organic Cimpounds. $6^{\text {th }}$ Edition. John Willey and Son Inc. Singapore.

Suparmi dan Prasetya, H. 2012. Isolation and Identification of Carotenoid Pigments of Yellow Ambon Banana Peel (Musa paradisiaca sapientum L.). Prosiding International Conference on Natural Sciences , pp. 83-91. Universitas Brawijaya. Malang
Tritianti, A dan Pranita, I. 2014. Limbah Kulit Pisang Sebagai Alternatif pengganti pewarna sintetis pada bedak tabur. Universitas Negeri Yogyakarta. Yogyakarta.

Utami. 2009. Potensi Daun Alpukat (Persea Americana Mill) Sebagai Sumber Anti Oksidan Alami. Jurnal Teknik Kimia. UPN Jawa Timur. 2 (1); 58-64

Wahyuni, D.T., dan S.B. Widjanarko. 2015. Pengaruh Jenis Pelarut Dan Lama Ekstraksi Terhadap Ekstrak Karotenoid Labu Kuning Dengan Metode Gelombang Ultrasonik. Jurnal Pangan dan Agroindustri. 3 (3); 390401. Malang 